Assiut Scientific Nursing Journal

http://asnj.journals.ekb.eg

http://www.arabimpactfactor.com

\title{
Contributing Factors to Non-adherence among Chronic Renal Failure Patients Undergoing Haemodialysis Sessions
}

\author{
Saleh Mohammed Mousa ${ }^{1}$, Asmaa Sayed Abd-Almageed ${ }^{2}$ \& Shimaa Hussein Mohammed ${ }^{3}$. \\ 1. Nursing Specialist in Dairout General Hospital, Assiut, Egypt. \\ 2. Assistant Prof of Medical Surgical Nursing, Faculty of Nursing, Assiut University, Egypt. \\ 3. Lecturer of Medical Surgical Nursing, Faculty of Nursing, Assiut University, Egypt.
}

\begin{abstract}
Background: Non-adherence to dialysis is a cause for concern as it leads to several life-threatening complications. Several factors can contribute to non-adherence in dialysis patients. The aims to identify factors contributing to nonadherence among chronic renal failure patients undergoing haemodialysis sessions. Methods: Research design: Descriptive research design.Setting : Dairout General Hospital at haemodialysis unit. Subjects :A purposive sample of 95 adults patients, male \& female, their age ranged from 18-65 years, undergoing haemodialysis and agreed to participate in the study. Tools : Tool (1):Patient assessment. Tool (2): Non-adherence contributing factors questionnaire among chronic renal failure patients. Results : Six categories of factors contributing to non-adherence among chronic renal failure patients undergoing haemodialysis sessions were identified. These were patient related factors, sociodemographic factors, psychological factors, therapy related factors, disease related factors and health care related factors.Conclusion: Non-adherence remains a major obstacle in the effective management of chronic kidney disease (CKD) patients. Recommendations:There is need for collaborative approach to devise measures that eliminate relevant contributing factors to non-adherence among chronic renal failure (CRF)patients.
\end{abstract}

\section{Keywords: Adherence, Chronic Renal Failure, Haemodialysis and Non-adherence.}

\section{Introduction}

Nonadherence defined as skipping one or more haemodialysis (HD) sessions in a 4-week period, shortening a dialysis session by $>10$ minutes in a month.(Safdar et al., 2013). Nonadherence to hemodialysis on the other hand remains a major obstacle in the management of End Stage Renal Disease (ESRD) population. Many patients with ESRD miss their haemodialysis sessions and place themselves at increased risk for hospitalization or mortality. (Naalweh et al., 2017).

Mortality rates for individuals with chronic kidney disease(CKD) remain high because of non-adherence and without adequate dialysis, death occurs from build-up of fluids and waste products in the body .Other complications of non-adherence to haemodialysis sessions include pulmonary oedema, hypertension, hospital readmissions and septicaemia.(Godfrey, 2018).

Skipping 1 dialysis session a month (or more) increases the risk of death by $30 \%$ compared to someone who regularly attends dialysis sessions. Compared to someone who dialyses a full 4 hours, 3 times a week, those dialysing for shorter times have an increased risk of death. $19 \%$ increased risk of death- if dialysis is between $3 \frac{1}{2}$ to 4 hours of dialysis. $34 \%$ increased risk of death- for less than $3 \frac{1}{2}$ hours of dialysis. This equates to losing 4 months per year of the life expectancy. (Hedayati et al., 2016).
Because of the detrimental effects and negative effects of non-adherence towards haemodialysis sessions among CRF patients, this need serious consideration as these impacts on the quality of life of CKD patients. Therefore, in order to formulate effective strategies that combat non-adherence in CKD patients, there's a need to systematically review,identify and explore the factors contributing to non-adherence towards haemodialysis sessions among CKD patients. Despite the evidence that indicates factors contributing to non-adherence towards haemodialysis sessions in CKD patients, there are no summative review on these factors in all management modalities. (Chironda \& Bhengu, 2016).

Interventions to improve adherence towards haemodialysis sessions need to target the contributing factors to enhance the quality of life. These may be patient related factors such as age, gender, level of education, health beliefs, and interpersonal communication, socioeconomic factors such as income status, employment status, social support of families, peer support, and transportation problems, psychological factors such as depression, stress, irrational thoughts, perceived physical health, disturbance in self_concept, and forgot, health care related factors such as availability of dialysis centers, accessibility of dialysis centers, strict selection 
criteria, and economic resources, therapy related factors such as muscle cramps, intra dialytic hypotension, chest pain, physical fatigue, and haemodialysis access clotted, disease related factors such as gastrointestinal problems, ureamia, bones disease, and skin problems.(Chironda \& Bhengu, 2016).

The nephrology nurse should be alert and had good understanding of the factors that contributing to nonadherence towards haemodialysis sessions among CRF patients, and know the subcategories of each factor to improve patients adherence and prevent non_adherence to haemodialysis sessions.(Griva et al., 2018).

\section{Significance of the study}

Nonadherence to dialysis treatment has been generally reported at rates between $8.5 \%$ and $22.1 \%$ worldwide and, in one study, as high as $86 \%$. Failure to attend all dialysis sessions, which is an important indicator of adherence to dialysis treatment, has also been noted at rates of $7 \% 32 \%$.

According to Dairout General Hospital records,in Assiut governorate, the number of haemodialysis patients in 2018 was 126 patients and there were approximately (18.2\%) weren't adhered to haemodialysis sessions. In 2019 the number of haemodialysis patients was 143 patients and there were $(18.8 \%)$ weren't adhered well to haemodialysis sessions. Also from the international research and the researcher four years experience it was noted that patients's knowledge about importance of adherence towards the dialysis sessions is inadequate. Therefore this study will be conducted to identify and explore factors contributing to non-adherence towards the dialysis sessions.

\section{Aim of the study}

The present study was carried out to identify factors contributing to non-adherence among chronic renal failure patients undergoing haemodialysis sessions.

\section{Research question}

What are contributing factors to non-adherence among chronic renal failure patients undergoing haemodialysis sessions?

\section{Patients \& Methods \\ Research design}

Descriptive research design was used.

\section{Research setting}

The study was conducted in Dairout General Hospital at haemodialysis unit,Assiut governorate, Egypt.

\section{Subjects}

A purposive sample of 95 adults patients, male \& female, their age ranged from 18-65 years, undergoing haemodialysis and agreed to participate in the study.
Sample size was selected according to formula

$$
n=\frac{N \times p(1-p)}{\left.\left[N-1 \times\left(d^{2} \div z^{2}\right)\right]+p(1-p)\right]}
$$

$\mathrm{N}=$ Total patients size in one year

$\mathrm{z}=$ Confidence levels are 0.85 and are equal to 1.96

$\mathrm{d}=$ The error ratio is 0.05

$\mathrm{p}=$ The property availability ratio and neutral $=0.50$

Tools

Two tools were utilized to achieve the aims of this study:-

Tool (1): Patient assessment: It was developed by the researcher after reviewing of literature to assess characteristics of those patients, it included:

(A): Sociodemographic data, such as age, sex, marital status, level of education, occupation, residence, type of family and household size in numbers.

(B): Medical data, it included duration of haemodialysis, number of sessions per week, hours of haemodialysis per session, type of vascular access, presence of chronic illnesses, when was the last time a medical professional talked to you about the importance of adherence to haemodialysis session, how often does a medical professional talk to you about the importance of staying for the entire dialysis time during haemodialysis session, during the last month how many times have you shortened your dialysis hours.

Tool (2):Non-adherence contributing factors questionnaire among chronic renal failure patients, it was developed by (Chironda\&Bhengu 2016) to identify factors contributing to nonadherence to dialysis sessions. This questionnaire divided into six categories and each category was divided into subcategories

- Patient related factors: (age, gender, level of education, health beliefs, interpersonal communication).

- Socioeconomic factors: (income status, employment status, social support of families, peer support, transportation problems).

- Psychological factors: (depression, stress, irrational thoughts, perceived physical health, disturbance in self_concept, forgot).

- Health care related factors: (availability of dialysis centers, accessibility of dialysis centers, strict selection criteria, economic resources).

- Therapy related factors : (muscle cramps, intra dialytic hypotension, chest pain, physical fatigue, haemodialysis access (grafts, fistulas, or catheter) clotted).

- Disease related factors : (gastrointestinal problems, ureamia, bones disease, skin problems ). 


\section{Scoring system}

The total number of questions were 29 questions, each question have two responses from 1:2. 1-no 2-yes therapy related factors score (6-12), psychological factors score (5-10), socioeconomic factors score (5-10), patient related factors score (5$10)$, health care related factore score (4-8), disease related factors score (4-8), total score (29-58).

\section{Ethical considerations}

Research proposal was approved from Ethical Committee in the faculty of nursing,Assiut University.There was no risk for study subject during application of research. The study followed common ethical principles in the clinical research. Informed consent was obtained from patients or guidance that were willing to participate in the study, after explanation of the nature and the purpose of the study. Confidentiality and anonymity were assured. Patients had the right to refuse to participate or withdraw from the study without any rational at any time. Patients's privacy was considered during collection of data.An official letter was sent to Dairout General Hospital to carry out this study.

\section{Procedure}

This study was carried out in three phases:

Preparatory phase

Tools development

A review of current and past, local and international related literature in the various aspects using books, articles, periodicals and magazines were done.

\section{Face validity and reliability}

Face validity was done by a panel of five expertise (2 medical staff from haemodialysis unit ) \& (3 nursing staff from the Medical-Surgical Nursing department) who reviewed the tools for clarity, relevance, comprehensiveness, understanding and applicability. Minor modifications were required and correction was carried out accordingly. Test reliability of the proposed tools was ascertained with Cronbach's alpha $=0.90$.

\section{Pilot study}

A Pilot study was conducted and implemented on $10 \%$ of sample (10 patients) in haemodialysis unit to test the applicability and clarity of the tools. According to this pilot study, no modifications were made to the tools, so those patients were included in the actual study sample. It had also provided an estimate of time needed to fill out the tools.

\section{Implementation phase}

- During this phase the researcher conducted the assessment process for the patients included in the study.

- Firstly, the researcher greeted the patients, introduced himself and purpose of study was explained to patients who agreed to participate in the study prior to any data collection.

- After taking the patient's oral agreement for voluntary participation in the study, each patient involved in the study was interviewed individually for filling (Tool I) patient assessment \& (Tool 2) factors contributing to non-adherence among chronic renal failure patients questionnaire.

- Each patient was met during session, for one session in the morning shift or evening shift or night shift according to haemodialysis sessions schedule. The session took about 20-30 minutes. One family member was present in the session for patien't support and increasing their sense of responsibility. Patients were allowed to ask questions in case of misunderstanding while listening and expressing interest.

- The collection of data lasted through the period from 1 January 2020 to April 2020.

\section{Statistical analysis}

Data entry was done using compatible personal computer by the researcher. All data was entered into statistical packages for the social sciences (SPSS) version 20.0 software for analysis and Excel for figures. The content of each tool was analysed, categorized and then coded by the researcher. Data were presented as number, percentage, mean, median, and standard deviation. Categorical variables were described by number and percent, where continuous variables described by mean and standard deviation (Mean, SD). 


\section{Results}

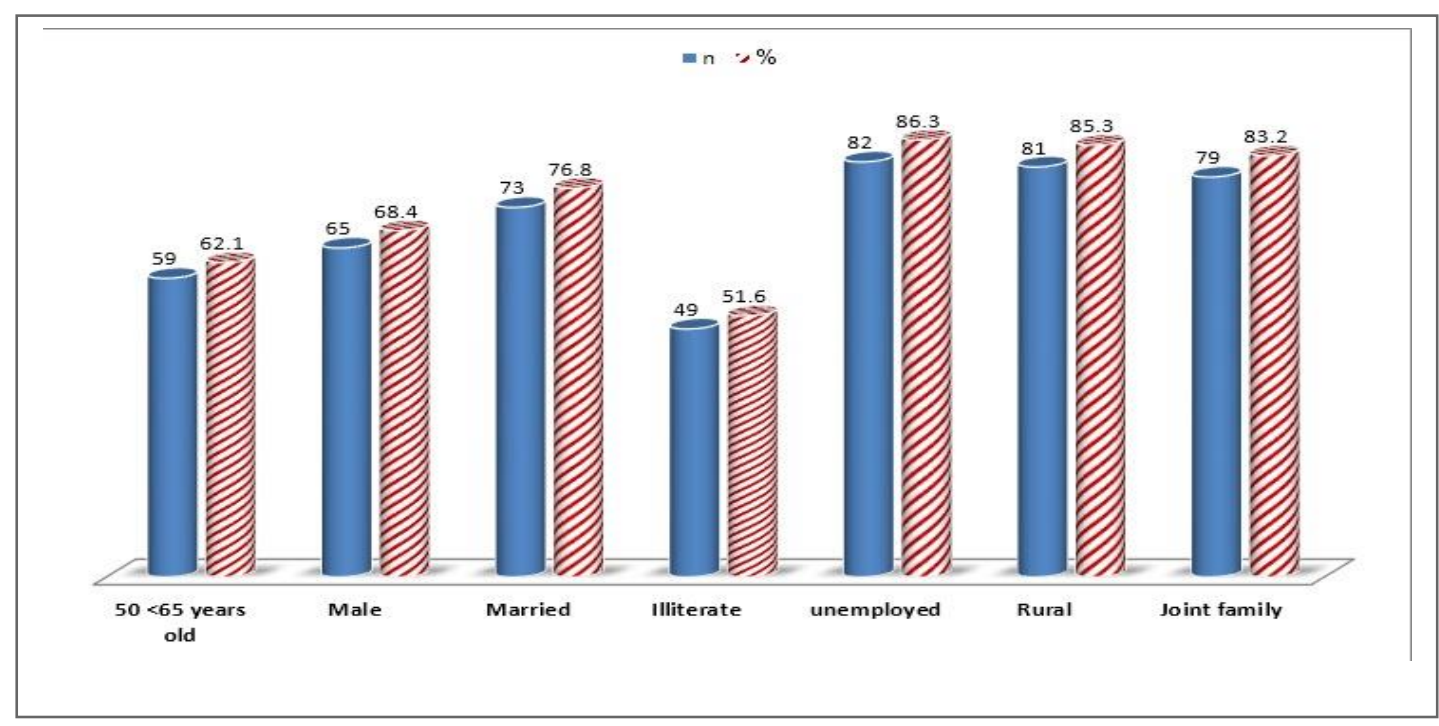

Fig (1): Frequency distribution of studied patients according to socidemographic data $(n=95)$

Table (1): Frequency distribution of studied patients according to medical data $(n=95)$.

\begin{tabular}{|l|c|c|}
\hline \multicolumn{1}{|c|}{ Variables } & N & \% \\
\hline 1-Duration of hemodialysis & & \\
\hline - Less than one years & 12 & 12.6 \\
\hline - 1-5 yrs & 46 & 48.4 \\
\hline - More than five years & 37 & 38.9 \\
\hline 2-Times of receiving hemodialysis per week & & \\
\hline - One day & 0 & 0.0 \\
\hline - Two days & 7 & 7.4 \\
\hline - Three days & 88 & 92.6 \\
\hline 3-Hours of hemodialysis per session & & \\
\hline - - h hours & 94 & 98.9 \\
\hline - More than 5 hours & 1 & 1.1 \\
\hline 4-Type of vascular access & & \\
\hline - Arteriovenous fistula & 93 & 97.9 \\
\hline - Arteriovenous graft & 2 & 2.1 \\
\hline 5-Presence of chronic illnesses & & \\
\hline - Diabetes mellitus & 13 & 13.7 \\
\hline - Hypertension & 74 & 77.9 \\
\hline - Cardiovascular disease & 28 & 29.5 \\
\hline - Pulmonary disease & 16 & 16.8 \\
\hline - Kidney disease & 94 & 98.9 \\
\hline - Endocrine disease & 1 & 1.1 \\
\hline - Tumors disease & 0 & 0.0 \\
\hline
\end{tabular}


Table (2): Frequency distribution for non-adherence contributing factors among chronic renal failure patients undergoing haemodialysis sessions $(\mathbf{n}=95)$

\begin{tabular}{|l|c|c|}
\hline \multicolumn{1}{|c|}{ Categories of factors contributing to non-adherence } & N & \% \\
\hline 1-Patient related factors: & Patient answer & 29.5 \\
\hline - Age & 28 & 30.5 \\
\hline - Gender & 29 & 84.2 \\
\hline - Level of education & 57 & 60.0 \\
\hline - Health beliefs & 37 & 38.9 \\
\hline - Interpersonal communication & & \\
\hline 2-Socioeconomic factors: & 69 & 72.6 \\
\hline - Income status & 12 & 12.6 \\
\hline - Employment status & 54 & 56.8 \\
\hline - Social support of families & 59 & 62.1 \\
\hline - Peer support & 68 & 71.6 \\
\hline - Transportation problems & & \\
\hline 3-Psychological factors: & 53 & 55.8 \\
\hline - Depression & 53 & 55.8 \\
\hline - Stress & 54 & 56.8 \\
\hline - Irrational thoughts & 54 & 56.8 \\
\hline - Perceived physical health & 54 & 56.8 \\
\hline - Disturbance in self_concept & 2 & 2.1 \\
\hline - Forgot & & \\
\hline 4-Health care related factore: & 58 & 61.2 \\
\hline - Availability of dialysis centers & 58 & 61.1 \\
\hline - Accessibility of dialysis centers & 45 & 47.4 \\
\hline - Strict selection criteria & 69 & 72.6 \\
\hline - Economic resources & & \\
\hline 5-Therapy related factors: & 82 & 86.3 \\
\hline - Muscle cramps & 46 & 48.4 \\
\hline - Intra dialytic hypotension & 39 & 41.1 \\
\hline - Chest pain & 81 & 85.3 \\
\hline - Physical fatigue & 38 & 40.0 \\
\hline - Hemodialysis access (grafts, fistulas, or catheter) clotted & 79 & 83.2 \\
\hline 6-Disease related factors: & 46 & 48.4 \\
\hline - Gastrointestinal problems & 83 & 87.4 \\
\hline - Uremia & 11 & \\
\hline - Bones disease & & \\
\hline - Skin problems & & \\
\hline
\end{tabular}

Table (3): Total mean for non-adherence contributing factors among chronic renal failure patients undergoing haemodialysis sessions $(\mathbf{n}=95)$

\begin{tabular}{|l|c|c|c|}
\hline \multicolumn{1}{|c|}{ Categories of factors contributing to non-adherence } & Minimum & Maximum & means \pm SD \\
\hline \hline Therapy related factors score & 6.00 & 10.00 & $8.84 \pm 1.3$ \\
\hline Psychological factors score & 5.00 & 10.00 & $8.01 \pm 1.06$ \\
\hline Socioeconomic factors score & 6.00 & 12.00 & $7.75 \pm 1.04$ \\
\hline Patient related factors score & 5.00 & 8.00 & $7.43 \pm 1.11$ \\
\hline Health care related factors score & 5.00 & 8.00 & $6.43 \pm 1.12$ \\
\hline Disease related factors score & 5.00 & 8.00 & $6.30 \pm .700$ \\
\hline
\end{tabular}


Table (4): Correlation between non-adherence contributing factors among chronic renal failure patients undergoing haemodialysis sessions and socidemographic data $(n=95)$.

\begin{tabular}{|c|c|c|c|c|c|c|c|}
\hline \multicolumn{2}{|c|}{ Socidemographic data } & \multirow{2}{*}{$\begin{array}{c}\begin{array}{c}\text { Patient } \\
\text { related } \\
\text { factors }\end{array} \\
.001\end{array}$} & \multirow{2}{*}{\begin{tabular}{|c|c|}
$\begin{array}{c}\text { Total } \\
\text { socioeconomic } \\
\text { factors }\end{array}$ \\
$.223^{*}$
\end{tabular}} & \multirow{2}{*}{\begin{tabular}{|c|c|}
$\begin{array}{c}\text { Total } \\
\text { psychologic } \\
\text { al factors }\end{array}$ \\
.117
\end{tabular}} & \multirow{2}{*}{$\begin{array}{c}\begin{array}{c}\text { Health care } \\
\text { related } \\
\text { factors }\end{array} \\
-.165\end{array}$} & \multirow{2}{*}{ 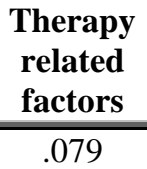 } & \multirow{2}{*}{ 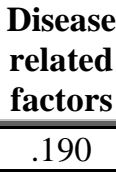 } \\
\hline rondr & Pearson Correlation & & & & & & \\
\hline gender & Sig. (2-tailed) & .992 & .030 & .260 & .111 & .449 & .065 \\
\hline \multirow{2}{*}{ Marital status } & Pearson Correlation & -.099 & .158 & -.122 & -.029 & .049 & -.028 \\
\hline & Sig. (2-tailed) & .339 & .126 & .239 & .782 & .640 & .790 \\
\hline \multirow{2}{*}{$\begin{array}{l}\text { Education } \\
\text { level }\end{array}$} & Pearson Correlation & .117 & .018 & .066 & -.143 & .013 & .019 \\
\hline & Sig. (2-tailed) & .257 & .865 & .526 & .170 & .897 & .855 \\
\hline \multirow{2}{*}{ occupation } & Pearson Correlation & $.210^{*}$ & $-.210^{*}$ & -.025 & .157 & .091 & .043 \\
\hline & Sig. (2-tailed) & .041 & .041 & .813 & .132 & .383 & .682 \\
\hline \multirow{2}{*}{ residence } & Pearson Correlation & -.055 & .040 & .027 & $-.297^{* * \pi}$ & -.088 & -.097 \\
\hline & Sig. (2-tailed) & .599 & .704 & .792 & .004 & .396 & .350 \\
\hline \multirow{2}{*}{$\begin{array}{l}\text { Type of } \\
\text { family }\end{array}$} & Pearson Correlation & -.104 & $-.239^{*}$ & -.011 & $-.203^{*}$ & -.049 & -.005 \\
\hline & Sig. (2-tailed) & .318 & .020 & .913 & .049 & .640 & .964 \\
\hline \multirow{2}{*}{$\begin{array}{c}\text { household } \\
\text { number }\end{array}$} & Pearson Correlation &,- 054 &,- 065 &,- 153 &,- 242 &,- 039 & .001 \\
\hline & Sig. (2-tailed) & .601 & .533 & .138 & .019 & .706 & .993 \\
\hline
\end{tabular}

**Correlation is significant at the 0.01 level (2-tailed).

*. Correlation is significant at the 0.05 level (2-tailed).

Table (5): Correlation between non-adherence contributing factors among chronic renal failure patients undergoing haemodialysis sessions $(n=95)$

\begin{tabular}{|c|c|c|c|c|c|c|c|}
\hline \multicolumn{2}{|c|}{ Items } & $\begin{array}{l}\text { Patient } \\
\text { related }\end{array}$ & $\begin{array}{c}\text { Total } \\
\text { socioecono }\end{array}$ & $\begin{array}{c}\text { Total } \\
\text { psychologic }\end{array}$ & $\begin{array}{l}\text { Health } \\
\text { care } \\
\text { related }\end{array}$ & $\begin{array}{l}\text { Therapy } \\
\text { related }\end{array}$ & $\begin{array}{l}\text { Disease } \\
\text { related }\end{array}$ \\
\hline \multirow{2}{*}{$\begin{array}{l}\text { Patient related } \\
\text { factors }\end{array}$} & $\begin{array}{l}\text { Pearson } \\
\text { Correlation }\end{array}$ & 1 & .145 & $.431^{* *}$ & .039 & -.147 & -.170 \\
\hline & Sig. (2-tailed) & & .162 & .000 & .710 & .156 & .099 \\
\hline \multirow{2}{*}{$\begin{array}{c}\text { Total } \\
\text { socioeconomic } \\
\text { factors }\end{array}$} & $\begin{array}{l}\text { Pearson } \\
\text { Correlation }\end{array}$ & .145 & 1 & .172 & $.306^{* *}$ & -.007 & -.029 \\
\hline & Sig. (2-tailed) & .162 & & .095 &, .003 & .945 & .783 \\
\hline \multirow{2}{*}{$\begin{array}{c}\text { Total } \\
\text { psychological } \\
\text { factors }\end{array}$} & $\begin{array}{l}\text { Pearson } \\
\text { Correlation }\end{array}$ & $.431^{* *}$ & .172 & 1 & -.192 & -.052 & -.074 \\
\hline & Sig. (2-tailed) & .000 & .095 & & .064 & .618 & .475 \\
\hline \multirow{2}{*}{$\begin{array}{l}\text { Health care } \\
\text { related factors }\end{array}$} & $\begin{array}{l}\text { Pearson } \\
\text { Correlation }\end{array}$ & .039 & $.306^{* *}$ & -.192 & 1 & .085 & -.098 \\
\hline & Sig. (2-tailed) & .710 & .003 & .064 & & .413 & .346 \\
\hline \multirow{2}{*}{$\begin{array}{c}\text { Therapy related } \\
\text { factors }\end{array}$} & $\begin{array}{l}\text { Pearson } \\
\text { Correlation } \\
\end{array}$ & -.147 & -.007 & -.052 & .085 & 1 & $.223^{*}$ \\
\hline & \begin{tabular}{|l|} 
Sig. (2-tailed) \\
\end{tabular} & .156 & .945 & .618 & .413 & & .030 \\
\hline \multirow{2}{*}{$\begin{array}{c}\text { Disease related } \\
\text { factors }\end{array}$} & $\begin{array}{l}\text { Pearson } \\
\text { Correlation }\end{array}$ & -.170 & -.029 & -.074 & -.098 & $.223^{*}$ & 1 \\
\hline & Sig. (2-tailed) & .099 & .783 & .475 & .346 & .030 & \\
\hline
\end{tabular}

**. Correlation is significant at the 0.01 level (2-tailed).

*. Correlation is significant at the 0.05 level (2-tailed). 
Table (6): Correlation between non-adherence contributing factors among chronic renal failure patients undergoing haemodialysis sessions and chronic disease $(n=95)$

\begin{tabular}{|c|c|c|c|c|c|c|c|}
\hline \multicolumn{2}{|c|}{ Items } & \multirow{2}{*}{$\begin{array}{r}\begin{array}{c}\text { Patient } \\
\text { related } \\
\text { factors }\end{array} \\
-.237^{*}\end{array}$} & \multirow{2}{*}{\begin{tabular}{|c|}
$\begin{array}{c}\text { Total } \\
\text { socioeconom } \\
\text { ic factors }\end{array}$ \\
-.084 \\
\end{tabular}} & \multirow{2}{*}{$\begin{array}{c}\begin{array}{c}\text { Total } \\
\text { psychologic } \\
\text { al factors }\end{array} \\
-.163\end{array}$} & \multirow{2}{*}{$\begin{array}{c}\begin{array}{c}\text { Health care } \\
\text { related } \\
\text { factors }\end{array} \\
.009\end{array}$} & \multirow{2}{*}{$\begin{array}{c}\begin{array}{c}\text { Therapy } \\
\text { related } \\
\text { factors }\end{array} \\
-.033\end{array}$} & \multirow{2}{*}{$\begin{array}{c}\begin{array}{c}\text { Disease } \\
\text { related } \\
\text { factors }\end{array} \\
-.130\end{array}$} \\
\hline \multirow{2}{*}{ Diabetes } & $\begin{array}{l}\text { Pearson } \\
\text { Correlation }\end{array}$ & & & & & & \\
\hline & \begin{tabular}{|l|}
$\begin{array}{l}\text { Sig. (2- } \\
\text { tailed) }\end{array}$ \\
\end{tabular} & .021 & .420 & .115 & .931 & .752 & .208 \\
\hline \multirow{2}{*}{ Hypertension } & $\begin{array}{l}\text { Pearson } \\
\text { Correlation }\end{array}$ & .047 & -.002 & $-.239^{*}$ & .118 & .101 & .124 \\
\hline & \begin{tabular}{|l|}
$\begin{array}{l}\text { Sig. (2- } \\
\text { tailed) }\end{array}$ \\
\end{tabular} & .650 & .984 & .020 & .257 & .331 & .231 \\
\hline \multirow{2}{*}{ Cardiovascular } & $\begin{array}{l}\text { Pearson } \\
\text { Correlation }\end{array}$ & -.106 & -.005 & -.010 & $.342^{* *}$ & .146 & .048 \\
\hline & \begin{tabular}{|l|}
$\begin{array}{l}\text { Sig. (2- } \\
\text { tailed) }\end{array}$ \\
\end{tabular} & .308 & .962 & .922 & .001 & .158 & .643 \\
\hline \multirow{2}{*}{$\begin{array}{c}\text { Pulmonary } \\
\text { disease }\end{array}$} & $\begin{array}{l}\text { Pearson } \\
\text { Correlation }\end{array}$ & $-.251^{*}$ & -.057 & -.053 & .116 & $.287^{* *}$ & .085 \\
\hline & \begin{tabular}{|l|}
$\begin{array}{l}\text { Sig. (2- } \\
\text { tailed) }\end{array}$ \\
\end{tabular} & .014 & .581 & .609 & .266 & .005 & .411 \\
\hline \multirow{2}{*}{ Kidney disease } & $\begin{array}{l}\text { Pearson } \\
\text { Correlation } \\
\end{array}$ & .133 & .075 & $.224^{*}$ & -.052 & .098 & .045 \\
\hline & \begin{tabular}{|l|} 
Sig. (2- \\
tailed)
\end{tabular} & .199 & .471 & .029 & .616 & .344 & .664 \\
\hline
\end{tabular}

**. Correlation is significant at the 0.01 level (2-tailed).

*. Correlation is significant at the 0.05 level (2-tailed).

Figure (1): Shows that the highest percentage of studied patients their ages ranged between 50-65 years old with amean age of $49.90 \pm 13.12$ years old, and the highest percentage of them were male, married and illiterate. As regard to occupation, residence and type of family, the majority of studied patients were unemployed, come from rural area, and live in joint family.

Table (1): Reflects that the highest percentage of studied patients their duration of haemodialysis from 1-5 years and receiving haemodialysis 3 days per week. Almost all of patients treated for each hemodialysis 4-5 hours. Regarding type of vascular access ,majority of patients use arteriovenous fistula, and complain of kidney disease and hypertension.

Table (2): Reveals that level of education, income status, irrational thoughts, perceived physical health, disturbance in self concept, economic resources, muscle cramps, and bone diseases were the most non-adherence contributing factors among chronic renal failure patients undergoing haemodialysis sessions respectively.

Table (3): Reveals that therapy related factors were the highest non-adherence contributing factors among chronic renal failure patients undergoing haemodialysis Sessions.

Table (4): Shows that there were highly statistically positive correlations were found between residence with health care related factors. Also, there were statistically positive correlations were found between gender with socioeconomic factors, occupation with patient related factors and socioeconomic factors, type of family with socioeconomic factors, health care related factors and household number with health care related factors .with $p=\leq 0.05$.

Table (5): Shows that there were highly statistically positive correlations were found between patient related factors with total psychological factors, and total socioeconomic factors with health care related factors. Otherwise, there were found between therapy related factors with disease related factors with $p$ $=\leq 0.05$.

Table (6): Shows that there were highly statistically positive correlations were found between cardiovascular disease with health care related factors and pulmonary disease with therapy related factors. Also,there were statistically positive correlations were found between diabetes with patient related factors and hypertension, kidney disease and pulmonary disease with total psychological factors and patient related factors. With $\mathrm{p}=\leq 0.05$.

\section{Discussion}

Non-adherence to dialysis is a cause for concern as it leads to several life-threatening complications. Several factors can contribute to non-adherence in 
dialysis patients which include patient related factors, socioeconomic factors, psychological factors, health care related factors, disease related factors, and therapy related factors.(Chironda \& Bhengu, 2016). Regarding the sociodemographic data, the highest percentage of studied patients their ages ranged between 50-65 years old with amean age of $49.90 \pm 13.12$ years old.These findings supported by Chironda \& Bhengu, (2016) who reported similarly that age is associated with non-adherence in CRF patients with mean age of $50.90 \pm 10.12$ years old.

Regarding sex,the highest percentage of studied patients were male .This result was congruent with Griva et al., (2014) who reported in their study that more than half of patients were male. Likewise similar to our results a study conducted by Chironda \& Bhengu, (2016) who revealed that slightly more than two thirds of patients were male and being male is consistently associated with non adherence.

In relation to marital status, the present study revealed that the majority of studied patients were married. As regarding level of education, the highest percentage of studied patients were illiterate.This study findings was in line with a study conducted by Smith et al., (2010) which revealed that most studied patients were married and illiterate. From researcher view, married patients have more responsibilities than single patients so they not_adherent to dialysis sessions.

According to occupation, the present study revealed that the majority of studied patients were unemployed. As regarding residence, results from data collected in this study showed that the majority of studied patients were residents in rural areas,and these findings supported by Chironda \& Bhengu, (2016) who reported similarly that most of studied patients were residents in rural areas and unempolyed. From researcher view, these patients have fatigue and exhaustion as a result from CRF.

Regarding medical data, results from data collected in this study showed that the highest percentage of studied patients their duration of haemodialysis from $1-5$ year,and receiving haemodialysis 3 days per week.Almost all of patients treated for each haemodialysis 4-5 hours. Regarding type of vascular access, the majority of studied patients use arteriovenous fistula. Chironda \& Bhengu, (2016) were in the same line as they mentioned in their study that their studied patients were received haemodialysis 3 days per week, 4-5 hours per session, and most of them used arteriovenous fistula. As regarding presence of chronic diseases, the present study documented that kidney disease and hypertension were present in majority of studied patients. Browne \& Merighi, (2010) \& Griva et al (2014) were in the same line as they mentioned in their study that their studied patients were complained with kidney disease and hypertension.

As regarding therapy related factors, which considered as side effects of haemodialysis that affect adherence of CKD patients to haemodialysis sessions. Our study results revealed that therapy related factors were the highest non-adherence contributing factors among chronic renal failure patients undergoing haemodialysis Sessions. Our results revealed that almost all of studied patients were affected by muscle cramps and cause them non adherents to haemodialysis sessions. This results were congruent with Meira et al., (2010) who reported similary that muscle cramps is a well known and distressing adverse effect that may arise during a haemodialysis sessions, closely related to the volume of ultrafiltration needed, which can reach an occurrence of 10-20\%.Also Lynch et al.(2014), Fidan et al., (2013), \& Figueiredo et al., (2012) were in the same line and all noted that muscle cramps are very common and lead to non-adherence to dialysis sessions and treatment.

Our results revealed that almost all of studied patients were affected by physical fatigue and made them non-adherent to haemodialysis sessions. In agreement with our results, Harilall, (2010) did a study where CRF patients on haemodialysis were found to experience physical symptoms such as tiredness, lack of energy, nausea and cramps post dialysis and these were causing limitations in activities of daily living.

As regarding psychological factors, Smith et al., (2010) stated that psychological factors as the most common barriers to haemodialysis sessions, predominantly involving lack of motivation. Kimmel et al., (1998) investigated the impact of psychosocial factors on behavioral compliance and survival in urban haemodialysis patients and depression was related to decreased adherence to haemodialysis sessions and treatment regimen,and this agree with current study which revealed that psychological factors affecting on adherence to haemodialysis sessions.

Our results revealed that more than half of studied patients were affected by irrational thoughts. Similarly to our results Williams, (2009) reported that irrational thoughts contribute to non-adherence among CRF patients.

More than half of studied patients were affected by perceived physical health. The previous findings were supported by Elsevier, (2009) who stated that patient's beliefs about their physical health are important because they influence adherence and adjustment to haemodialysis sessions and this agree with current results. 
Our results revealed that more than half of studied patients were affected by disturbance in self_concept and affect their adherence to haemodialysis sessions. The same results was supported by Zalai et al., (2012) who investigated in their study that disturbance in self concept lead to decrease level of adherence to haemodialysis sessions because of feeling of loss of control and low self esteem.

Regarding Socioeconomic Factors, in studied patients the highest percentage of studied patients were low income status. This study findings were in line with a study conducted by Vivekanand et al., ;(2013) which revealed that people in the lowest socioeconomic quartile are a $60 \%$ greater risk of CKD than those who are in the highest quartile.

Regarding patient related factors, our study findings revealed that the highest percentage of studied patients were illiterate. This finding was supported by Chironda et al., (2014) who reported that low education and illiteracy have been found to cause decreased adherence due to poor correlation with knowledge of disease and treatment.

As regarding health care related factors, our results revealed that the majority of studied patients were affected by economic resources and made them nonadherent to their haemodialysis sessions. The same results was supported by Sayed et al., (2014) who investigated that the majority of patients live far from existing dialysis centers and have to travel long distances to receive dialysis, and these patients have no economic resources, resulting in dialysis inadequacy and frequent disruption of work that leads to job losses and consequent non-adherence and non-engagement with treatment regimen.

As regarding disease related factors, our results revealed that almost all of studied patients were affected by bones disease which caused them nonadherent well to haemodialysis sessions and prescribed schedule. Bones disease are the most frequently experienced problems in CRF patients undergoing haemodialysis sessions which are considered disease related factors.

This study findings were in line with a study conducted by Vivekanand et al., (2013) which revealed that the majority of patients had bones disease and made them non-adherent well to haemodialysis sessions. This may occur because of lack of calcium in the body and muscle cramps and physical fatigue which occur during haemodialysis sessions as Rocco \& Burkart, (1993) reported.

The present study illustrated that therapy related factors were the highest non-adherence contributing factors among CRF patients undergoing haemodialysis sessions then psychological factors. These findings were in the same line with Chironda \& Bhengu, (2016) who reported that therapy related factors were the most common non-adherence contributing factors among CRF patients undergoing haemodialysis sessions.

The present study illustrated that bones disease was the highest category of factors contributing to nonadherence, while forgot was the lowest category of factors contributing to non-adherence among CRF patients undergoing haemodialysis sessions. On the other hand this finding contradicted by Brekke et al., (2004) \& Shemesh et al., (2004) who reported that forgetting haemodialysis session is a major contributor to non-adherence among CRF patients.

The present study confirmed that there were highly statistically positive correlations were found between patient related factors with total psychological factors, and total socioeconomic factors with health care related factors. Otherwise, there were found between therapy related factors with disease related factors with $\mathrm{p}=\leq 0.05$.

Also in an agreement with our study results \&from the researcher's point of view,patient related factors were highly statistically positive correlations with psychological factors. The researcher noted that younger age was associated with psychological problems such as depression, stress, disturbance in self_concept. This supported by our study results.

Also the researcher noted that there were highly statistically positive correlations were found between socioeconomic factors with health care related factors, the researcher found that patients with low income status were affected by availability and accessibility of dialysis centers, so these patients had transportation problems and made them non-adherent to haemodialysis sessions.

Also the present study showed that there were highly statistically positive correlations were found between cardiovascular disease with health care related factors, and pulmonary disease with therapy related factors. Also, there were statistically positive correlations were found between diabetes with patient related factors and hypertension, kidney disease and pulmonary disease with total psychological factors and patient related factors with $\mathrm{p}=\leq 0.05$.

The present study also confirmed that there were highly statistically positive correlations were found between residence with health care related factors. Also, there were statistically positive correlations were found between gender with socioeconomic factors, occupation with patient related factors and socioeconomic factors, type of family with socioeconomic factors, health care related factors and household numbers with health care related factors with $\mathrm{p}=\leq 0.05$.

In conclusion, from the researcher's experience with CRF patients undergoing haemodialysis sessions, the 
results of this study apply to the reality that occurs with CRF patients and the purpose of this study was achieved.

\section{Conclusion}

The provision of CKD comprehensive patient care in terms of haemodialysis sessions is crucial in slowing the progression and complications of CKD. Nonadherence to haemodialysis sessions and treatment is a cause for concern as it leads to several life_threatening complications. Excellence in care of CKD patients requires the identification of factors that contribute to non-adherence as this is the cornerstone for management of CKD. Therefore, there is need to formulate effective strategies that combat factors contributing to non-adherence in CKD patients.

\section{Recommendations}

1- The health team should be aware of the factors contributing to non-adherence among CRF patients undergoing haemodialysis and subcategories of each category.

2- Simple educational pamphlet for haemodialysis patients and their families about the importance of adherence and negative effects and complications of non-adherence to dialysis sessions to improve adherence to haemodialysis sessions should be available in haemodialysis unit and outpatient renal clinics.

3- Continuous educational program to improve patient's knowledge about the importance of adherence and negative effects and complications of non-adherence to dialysis sessions.

\section{References}

- Browne T., Merighi J., (2010): Barriers to adult haemodialysis patients self management of oral medications. Am J kidney Dis 56:547-557.

Brekke HK, Sunesson Å, Axelsen M., Lenner R., (2004): Attitudes and barriers to dietary advice aimed at reducing risk of type 2 diabetes in first degree relatives of patients with type 2 diabetes. $\mathbf{J}$ Hum Nutr Dietetics 17: 513-521.

- Chironda G., Bhengu B., (2016): Contributing Factors to Non_Adherence among Chronic kidney Disease (CKD) Patients:ASystematic Review of Literature \& Clinical Reviews, vol. 02, no.04.

- Chironda G., Manwere A., Nyamakura R., Chipfuwa T., \& Bhengu B., (2014): Perceived health status and adherence to haemodialysis by End Stage Renal Disease (ESRD) Patients: A case of a central Hospital in Zimbabwe. IOSR Journal of Nursing and Health Sciences 22:31.
- Elsevier B., (2009): Haemodialysis patients beliefs about renal failure and its treatment, patient counselling and education. Am J Med 53: 189-196.

- Fidan F., Alkan B., Tousun A., Altunoglu A., \& Ardicoglu O., (2013): Quality of life and correlation with musculoskeletal problems, hand disability and depression in patients with haemodialysis. Int J Rheum Dis.

- Figueiredo AE, Goodlad C., Clemenger M., Haddoub S., \& McGrory J., (2012): Evaluation of physical symptoms in patients on peritoneal dialysis. Int J nephrol.

- Griva K., Lai A., Lim H., Zhenli Y., Foo M., (2014): Non-adherence in patients on Peritoneal Dialysis: ASystematic Review. Plos ONE 9 :e89001.

- Godfrey K., (2018): Patient adherence andadjustment in renal dialysis.Hong Kong Journal of Nephrology, vol. 19, pp.19_27.

- Harilall B., (2010): Experiences of patients on haemodialysis and continuous ambulatory peritoneal dialysis in end stage renal disease: an exploratory study at a tertiary hospital in KwaZuluNatal (Doctoral dissertation). University of KwaZuluNatal.

- Hedayati S., Daniel D., Cohen S., Comstock B., Cukor D., Diaz-Linhart Y., Dember L., Dubovsky A., Greene T., Grote N., Heagerty P., Katon W., Kimmel P., Kutner N., Linke L., Quinn D., Rue T., Trivedi M., Unruh M., Weisbord S., Young B., \& Mehrotra R., (2016): Rationale and design of a trial of sertraline vs. cognitive behavioral therapy for end-stage renal disease patients with depression (ASCEND). Contemp Clin Trials 47: 1-11.

- Kimmel P., Thamer M., Richard C., \& Ray N., (1998): Psychiatric illness in patients with endstage renal disease. Am J Med 105: 214-221.

- Lynch P., Abate M., Suh H., \& Wadhwa N., (2014): Magnesium and Muscle Cramps in End Stage Renal Disease Patients on Chronic Haemodialysis. Adv Nephrol.

- Meira F., Figueiredo A., Zemiarcki J., Pacheco J., \& Poli-de-Figueiredo E., (2010): Two variable sodium profiles and adverse effects during haemodialysis: a randomized crossover study. Ther Apheresis Dialysis 14: 328-333.

- Naalweh, K., Barakat, M., Sweileh, M., Al-Jabi. S., \& Zyoud. S., (2017): Treatment adherence and perception in patients on maintenance haemodialysis: Across - Sectional study from Palestine, BMC Nephrology, vol. 18, no.1, article no. 178 
- Rocco M., Burkart J., (1993): Prevalence of missed treatments and early sign- offs in haemodialysis patients.J Am Soc Nephrol 5: 11781183.

- Safdar N., Baakza H., Kumar H., Naqvi S., (2013): Non-compliance to diet and fluid restrictions in haemodialysis patients. J Pak Med Assoc.; 45(11):293-5.

- Sayed M., Abdelatty M., ELRawy B, Yasser M., \& Salman H., (2014): Assessment of socioeconomic burden of haemodialysis on ESRD patients in Suez Canal cities \& Elarish. Am J Res Comm 2: 7.

- Shemesh E., Shneider B., Savitzky J., Arnott L., \& Gondolesi G., (2004): Medication adherence in paediatric and adolescent liver transplant recipients. Paediatrics 113: 825-832.

- Smith K., Coston M., Glock K., Elasy T., \& Wallston K., (2010): Patient Perspectives on fluid management in chronic haemodialysis. J Renal Nutri 20:334-341.

- Vivekanand J., Guillermo G., Kunitoshi I., Zou l., \& Saraladev N., (2013): Chronic kidney disease; Global dimension and perspectives. The Lancet Publication.

- Williams M., (2009): Management of diabetes in dialysis patients. Curr Diabetes Rep 9: 466-472.

- Zalai D., Szeifert L., \& Novak M., (2012): Psychological distress and Depression in patients with chronic kidney disease. In Seminars in dialysis 4: 428- 438. 